\title{
Cosmic-ray observatory in Argentina gets go-ahead
}

[MUNICH] Site work for what will be the world's largest cosmic-ray observatory is about to begin in Argentina, after a consortium of 53 institutes in 19 countries signed an agreement last month.

The Pierre Auger Southern Observatory, in Mendoza province, will study ultra-highenergy cosmic particles whose origin is unknown and which are so rare that less than a dozen have so far been detected. They generate showers of secondary particles when they hit the Earth's atmosphere.

The US $\$ 50$ million observatory will comprise 1,600 surface detectors placed at 1.5kilometre intervals over an area of 3,000 square kilometres, complemented by four optical telescopes. The detectors - water tanks equipped with photomultipliers - will measure the so-called Cherenkov radiation generated in the water when the secondary particles hit at Earth level. The telescopes will detect the luminous traces in the sky created by particle showers.

The combined data will allow the direction, energy and mass of the primary particles to be determined much more accurately than at smaller cosmic-ray observatories, such as those in Akeno, Japan, and Utah, USA.

The largest single contributor to the Pierre Auger project is Argentina. The central and Mendoza governments have between them put up US\$15 million, which will be used primarily to prepare the infrastructure of the site, an elevated desert plain just east of the Andes.

Roads and a research station will be built in the province's capital, Malargüe. Data from components scattered around the region will be sent to the research station using mobile-telephone technology.

Brazil, France, Mexico, Britain and the United States will work with Argentina on the water-tank array, while Germany and Italy will provide the telescope technologies.

The observatory should be complete by 2003. According to a spokesman, Alberto Etchegoyen, of the National Atomic Energy Commission's Tandor Laboratory in Buenos Aires, data may be collected as soon as 2001, when many of the detectors will be in place.

Although low-energy cosmic-ray particles with energies of a few million electron volts are plentiful — one particle strikes every square metre of the earth every second ultra-high-energy particles of over $10^{20}$ electron volts, which interest scientists in the Pierre Auger collaboration, strike one square kilometre every century. "It is therefore obviously important to cover as much of the sky as possible," says Hans Blümer, a spokesman and head of the Institute for Nuclear Physics at the Forschungszentrum Karlsruhe.

The collaboration decided in 1996 to build a 'twin' Northern Observatory in Utah, of the same size, as soon as funding is found for the project.

For Blümer, the project is a triumph of "grass-roots science". As a large-scale project organized by a consortium of small institutes, he says, "no single very large institute is in charge". He praises the organizational skills of the project's pioneers, Nobel laureate James Cronin, head of the Enrico Fermi Institute at the University of Chicago, and Alan Watson, professor of astrophysics at the University of Leeds in Britain, who first proposed the project eight years ago.

Etchegoyen says the observatory will provide a tremendous boost for young Argentinian scientists. He believes it will encourage funding agencies to create more fellowships for young astrophysicists, which is important "because the physics community here is growing old".

Alison Abbott

\section{Canadian scientists win over rare species}

[ MONTREAL] Canada's federal government has announced that eight further scientists are being added as voting members to the committee that identifies which species are assigned to the country's endangered list.

The move comes in the wake of a letter written by more than 600 scientists to the prime minister, Jean Chrétien, complaining that political considerations prevented scientific principles from being followed in determining which species should be listed as endangered (see Nature 398, 9; 1999). It said the government had abandoned habitat protection as an en element of the legislation.

"In effect, [they are] restoring the vote that was taken away. That's great news," says Jamie Smith, of the University of British Columbia's Centre for Biodiversity Research, who helped draft the letter.

The eight scientists whose votes are restored will chair specialist groups on the Committee on the Status of Endangered Wildlife in Canada, which includes representatives from federal, provincial, territorial and private agencies along with independent experts.

Christine Stewart, Canada's environment minister, said she believes that the change to the committee will "ensure its continued scientific integrity".

\section{Court suspends pioneering gene deal in Yellowstone}

[WASHINGTON] A pioneering but controversial agreement that would have allowed Yellowstone National Park to collaborate with a Californian biodiversity company has been suspended by a US court. The plan to exploit the commercial potential of the park's biota was blocked for failing to provide a full environmental impact statement.

Judge Royce Lambarth of the US District Court for Washington ruled last week that the National Park Service, which runs the park, should subject its agreement with Diversa of San Diego to a formal environmental assessment.

The assessment, which will take place under the terms of the National Environmental Protection Act, will require the park service to compare the environmental impact of the agreement with alternative policies.

Yellowstone struck the deal - announced by US vice-president Al Gore in 1997 — to ensure that it will share in any bonanza resulting from the commercial use of genetic material from its plants and microbes.

The park's geothermal springs were the original home of the enzyme Taq polymerase, which is used worldwide in polymerase chain reaction (PCR) equipment. Hoffman-La Roche holds patents for its use and the national park stands to gain nothing from its huge commercial success.

But critics say that the deal is not in keeping with the mission of the national parks, and last year sued the park service to halt it (see Nature 392, 117; 1998).

Judge Lambarth ruled that the agreement amounted to a significant change of US government policy on bioprospecting on land owned by the federal government, and as such should be subject to public review.

The judge did not rule on other areas of contention, including whether the royalty payments should be published. Immediately after the ruling, the park service said it would suspend the agreement until the environmental assessment was completed.

Jay Short, chief executive of the San Diego-based company, responded to the judgement by announcing that Diversa, while complying with it, would voluntarily pay royalties to Yellowstone from any products which it derives from the bioprospecting it has already undertaken at the national park, pending the environmental assessment.

The small environmental groups that have attacked the agreement welcomed the judgement. "It effectively prevents the exploitation of our national parks solely for commercial gain," says Joseph Mendelson, legal director of the Center for Technology Assessment in Washington. Colin Macilwain 